\title{
O caso Schreber: a expressão da escrita do trabalho clínico
}

Thais Augusto Gonçales Zanoni*1

Henriques, ao revisitar o caso Schreber sob a ótica de Freud, nos convida a um mergulho na articulação de questões clínicas relacionadas aos conteúdos que se expressam através da escrita. Escrita do fazer clínico e do paciente, em que ambos, ao se utilizarem do recurso de linguagem para transmitir o que se propõem, nos oferecem algo além. Em outras palavras, deixa-se escapar também a realidade psíquica pela qual o processo discursivo e suas reflexões sobre o caso são afetados.

Talvez, exatamente por isso, esse texto constitui-se como fundamental pesquisa para aqueles que se interessam pela transmissão da clínica sob os preceitos psicanalíticos do método clínico. E, ao pensarmos sobre a tradição da Psicopatologia Fundamental na qual prima o pathos em sua manifestação particular, no que se refere à subjetividade, esse fenômeno da escrita se confirma como um rico material de estudo.

O caminho percorrido pelo autor em torno de suas reflexões se dá com maestria. Com cuidadosa atenção para com o leitor, Henriques

*1 Mestranda na Pontifícia Universidade Católica de São Paulo-PUC-SP (São Paulo, SP. Br). 
organiza o texto construindo um percurso esclarecedor, enlaçando-nos em uma leitura acessível e agradável. Propõe, por meio de um esboço de divisão cronológica para a escrita de Schreber e para o ensaio de Freud, um diálogo com os principais conceitos referentes às psicoses.

Inicialmente é apresentada a autobiografia de Schreber - Memórias de um doente dos nervos — salientando-se os conteúdos relevantes dessa obra que são tratados no decorrer do livro, com especial enfoque para a discussão acerca do estilo literário e o posicionamento de Schreber como autor, associando-se aos temas que envolvem a psicose e a literatura. Pela sua autobiografia, Schreber encontra na escrita um apaziguamento dos fenômenos psicóticos reduzindo a "invasão do Outro a seu corpo".

Em um segundo momento, Henriques evoca as interpretações de Freud, Lacan e de outros comentadores analisando metodologicamente esses textos que versam sobre Schreber e sobre o ensaio de Freud. Questões de maior complexidade teórica com relação à metapsicologia freudiana e a concepção de Lacan acerca das psicoses são discutidas. Sobre este último, o autor dedica uma parte significativa do texto apresentando a compreensão linguístico-estrutural do fenômeno da psicose centrando-se na releitura lacaniana do caso Schreber.

Mais adiante, de forma bastante interessante, o autor expõe o estilo 570 literário do ensaio de Freud. Nesse ponto, Henriques destaca o caráter mimético expresso na escrita do caso Schreber, revelando que tanto Freud quanto Schreber "pareciam temer o fantasma do plágio que ronda seus escritos". Tal manifestação é abordada pelo autor considerando-se o contexto socio-histórico no qual Freud se encontrava enquanto formulava esse ensaio. Trata-se de um momento em que o plágio foi motivo de desavenças teóricas entre Freud e Alfred Adler, e, logo em seguida, com Carl Gustav Jung. A angústia referente à sua voz autoral e a originalidade no campo das psicoses traz características marcantes para o texto freudiano.

Ao longo de todo o livro de Henriques, apreende as principais questões teóricas referentes às psicoses o que permite construir o aporte necessário para a compreensão do funcionamento psíquico que se expressa pela escrita de Schreber e de como esta afeta o estilo literário de Freud.

Abordando desde os temas relacionados à escrita de Schreber, aos conceitos metapsicológicos acerca das psicoses somados às leituras freudianas, lacanianas e de alguns outros autores, somos direcionados para a compreensão de seu objeto de estudo: o ensaio de Freud sobre Schreber.

Pelas revelações deste estudo, torna-se pertinente a transposição destas questões referentes à escrita para nossas próprias vivências clínicas. Afinal, como indica o autor citando Miller, uma sessão de análise é sempre um esforço de poesia. Somado a isto, podemos pensar a escrita como sintoma e expressão 


\section{RESENHAS BIBLIOGRÁFICAS}

do psiquismo, do clínico e do paciente, especialmente quando retratamos um estudo de caso. Logo, somos levados a considerar o "contar-se", e a transmissão deste ato para o leitor, um processo de dar palavras ao pensar, tratando-se de um dos motivos que tornam a escrita de Henriques uma proveitosa leitura.

Em suma, a nós, leitores, apresenta-se um percurso instigante que contempla a escrita sobre a clínica e nos convoca de forma sublime a pensar a respeito do que se manifesta, muitas vezes de forma inconsciente, através da narrativa. Como coloca Giacóia Jr. (2013), o pensamento é um propósito que só se atinge em diálogo com a poesia. $\mathrm{E}$, se a poesia possibilita a articulação com outros significantes, este texto semeia tantos outros deslizamentos reflexivos.

\section{Referências}

Giacóia Jr., O. (2013). Heidegger urgente: introdução a um novo pensar. São Paulo: Três Estrelas.

Citação/Citation: Zanoni, T. A. G. (2016, setembro). O caso Schreber: a expressão da escrita do trabalho clínico. Resenha do livro Freud e a narrativa paranoica: Schreber revisitado. Revista Latinoamericana de Psicopatologia Fundamental, 19(3), 569-571.

Editor do artigo/Editor: Profa. Dra. Sonia Leite

Recebido/Received: 14.12.2015/ 12.14.2015 Aceito/Accepted: 29.1.2016 / 1.29.2016

Copyright: (C) 2009 Associação Universitária de Pesquisa em Psicopatologia Fundamental/ University Association for Research in Fundamental Psychopathology. Este é um artigo de livre acesso, que permite uso irrestrito, distribuição e reprodução em qualquer meio, desde que o autor e a fonte sejam citados / This is an open-access article, which permits unrestricted use, distribution, and reproduction in any medium, provided the original authors and sources are credited.

\section{Thais Augusto Gonçales Zanoni}

Psicóloga; Mestranda em Psicologia Clínica pela Pontifícia Universidade Católica de São Paulo - PUC-SP (São Paulo, SP, Br.); Especialista em Saúde Mental, Psicopatologia e Psicanálise pela Pontifícia Universidade Católica do Paraná - PUC-PR (Curitiba, PR, Br.); psicanalista; Pesquisadora do Laboratório de Psicopatologia Fundamental.

Rua Tatuapé, 1989/112

03066-010 São Paulo, SP, Br

thaisagz.psi@gmail.com

This is an open-access article, which permits unrestricted use, distribution,

\section{(cc) BY-NC} and reproduction in any medium for non-commercial purposes provided the original authors and sources are credited. 